\title{
Simultaneous Paired Analysis of Numerical Chromosomal Aberrations and DNA Content in Osteosarcoma
}

\author{
M. Serra, Ph.D., M. Tarkkanen, M.D., Ph.D., N. Baldini, M.D., Ph.D., K. Scotlandi, Ph.D., \\ M. Sarti, M.D., Ph.D., D. Maurici, Ph.D., M.C. Manara, M.D., Ph.D., S. Benini, B.Sc., P. Bacchini, M.D., \\ S. Knuutila, Pr, P. Picci, M.D., Ph.D. \\ Laboratorio di Ricerca Oncologica, Istituti Ortopedici Rizzoli (MS, NB, KS, MS, DM, MCM, SB, PP), \\ Bologna, Italy; Department of Medical Genetics, Haartman Institute, University of Helsinki and \\ Laboratory of Medical Genetics, Helsinki University Central Hospital, Helsinki, Finland (MT, SK); and \\ Servizio di Anatomia Patologica, Istituti Ortopedici Rizzoli (PB), Bologna, Italy
}

Relatively little is known about the biologic relevance of numerical chromosomal changes in relation to DNA content in osteosarcoma. In this study, by using a series of human osteosarcoma cell lines, we standardized a method for the assessment, on the same nuclei specimen, of both specific chromosome copy numbers by fluorescence in situ hybridization (FISH) and the DNA content by static cytofluorometry or image cytometry. On the same cell lines, we also evaluated the DNA content by using flow cytometry and the chromosome number distribution by metaphase analysis. Comparison between these different methods showed that DNA ploidy level as determined by FISH or metaphase analysis is frequently lower than the ploidy pattern as defined by cytometric methods. By using comparative genomic hybridization, we were able to demonstrate that these discrepancies were due to the presence of several unbalanced chromosome aberrations, specifically gains and high-level amplifications, which affect the total DNA content with less effect on the total chromosome number. Thus, evaluation of DNA ploidy in osteosarcoma cells is needed for a correct interpretation of FISH or cytogenetic data concerning numerical chromosomal changes. Evaluation of tumor ploidy in a series of clinical samples demonstrated that in high-grade

Copyright $(2001$ by The United States and Canadian Academy of Pathology, Inc.

VOL. 14, NO. 7, P. 710, 2001 Printed in the U.S.A

Date of acceptance: February 27, 2001

This work was supported by grants from Federazione Italiana per la Ricerca sul Cancro (F.I.R.C.), from the Associazione Italiana per la Ricerca sul Cancro (A.I.R.C.), from the Istituti Ortopedici Rizzoli (Ricerca Corrente and Ricerca Finalizzata), and by the Clinical Cancer Research Institute of Helsinki University Central Hospital and Leiras Research Foundation (Finland).

Address reprint requests to: M. Serra, Ph.D., Laboratorio di Ricerca Oncologica, Istituti Ortopedici Rizzoli, Via di Barbiano 1/10, I-40136 Bologna, Italy; e-mail: massimo.serra@ior.it; fax: ++39-051-6366761. osteosarcoma, flow cytometry sometimes may give false results because of the presence of high proportions of contaminating, nonneoplastic cells that cannot be excluded from the flow cytometric assessment but that do not interfere with the evaluation of DNA ploidy by static cytofluorometry or image cytometry, in which only tumor cells are selected for the analysis. The possibility of using this method to evaluate, on the same nuclei sample, both specific chromosomal aberrations and DNA ploidy may allow a better determination of numerical chromosomal changes that may be relevant for the biologic behavior of osteosarcoma.

KEY WORDS: CGH, Cytometry, FISH, Osteosarcoma, Ploidy.

Mod Pathol 2001;14(7):710-716

The analysis of DNA content in tumor cells has been reported as a useful means to define the malignant potential of human cancers (1-3). However, routine evaluation of tumor ploidy in bone tumors has been quite limited and, in comparison with other neoplasms, studies about the actual biological impact of DNA content in osteosarcoma (OS), the most common malignant tumor of bone, are still quite few (4-9). Moreover, no data are available about the relation between DNA content and specific numerical chromosomal changes that may be relevant for the pathogenesis of OS.

Genomic alterations which lead to numerical chromosomal aberrations and to an altered ploidy pattern can be assessed by several methods. Flow cytometry can be considered the standard and most commonly used technique for ploidy analysis in solid tumors. However, the application of flow cytometry to musculoskeletal tumors has been severely limited by the considerable technical diffi- 
culties in disaggregating the tissue specimen into a single cell suspension, which is required for a reliable analysis $(8,10)$. Moreover, in mineralized musculoskeletal tumors, flow cytometry may not provide an accurate measurement of DNA content because of the possible contamination with nonneoplastic cells (such as stromal cells, granulocytes, or lymphocytes) and the presence of damaged tumor cells or debris derived from extracellular matrix, which cannot be completely excluded from the analysis and can interfere with the assessment.

Because flow cytometry cannot give any information about specific chromosome copy numbers, other methods can be used to detect numerical chromosomal changes. In particular, metaphase analysis of solid tumors is a good approach for the detection of numerical and structural chromosomal changes by using in vitro short-term cultures, although a potential danger of loss of genetic material and selection of fast-growing subpopulations cannot be ruled out (11). To overcome this problem, the analysis of chromosome copy number distribution can be reliably performed by fluorescence in situ hybridization (FISH) with several centromeric probes, a method that allows the evaluation of chromosome number without culturing (12). Interphase cytogenetics by FISH is being increasingly used to determine the presence of numerical aberrations in human solid tumors because, as compared with flow cytometry and metaphase analysis, FISH can give more precise information about such aberrations in tumor cells. Moreover, by using FISH, minor cell populations showing polyploidization can be more easily revealed, enabling the detection of different cell populations within one tumor that may appear homogeneous with the other techniques (12-13).

The analysis of chromosomal changes in tumors is also possible with comparative genomic hybridization (CGH; 14). CGH is a powerful technique that can detect numerical chromosomal changes (gains and losses) larger than 5-10 megabases on the whole genome in a single hybridization (15-17). However, CGH can reveal only the average DNA content of the tumor sample, without the possibility of detecting intratumor heterogeneity (15). Moreover, balanced translocations and ploidy shifts (i.e., true tetraploidy) are undetectable, unbalanced rearrangements being the ideal target of CGH (15, 18).

In this context, the use of several, complementary techniques may help to obtain a more reliable estimation of specific numerical chromosomal changes in relation to the DNA content. In this study, by using a series of human OS cell lines, we have standardized a method for the assessment, on the same nuclei sample, of both specific chromosomal copy number by interphase FISH and of DNA content by static cytofluorometry or image cytometry. On the same cell lines, we also evaluated the DNA content by flow cytometry, the total chromosome number by using Giemsa-stained metaphases, and the presence of unbalanced genetic aberrations by CGH. The results obtained with these different approaches were then compared to define the most reliable method for the assessment of DNA content in OS cells. Finally, we assessed the ploidy level in a series of clinical OS samples to define the applicability of cytometric evaluation of ploidy to cytological samples obtained directly from clinical specimens.

\section{MATERIALS AND METHODS}

\section{Cell Lines}

The six human OS cell lines used in the present study were established at the Laboratorio di Ricerca Oncologica of the Istituti Ortopedici Rizzoli (Bologna, Italy) as follows: IOR/OS9 cell line was established from a bone metastasis of a high-grade, osteoblastic OS; IOR/OS10 from a primary, highgrade, fibroblastic OS; IOR/OS14 from a primary, small cell OS; IOR/OS15 and IOR/MOS from two primary, high-grade, osteoblastic OS; and SARG from an anaplastic high-grade OS (19-22).

\section{Paired Assessment of DNA Nuclear Content and Numerical Chromosomal Aberrations}

For the simultaneous paired analysis of DNA nuclear content and numerical chromosomal changes on the same nuclei specimen, nuclei were isolated from OS cell lines by treatment with hypotonic solution $\left(\mathrm{KCl}, 0.04 \mathrm{M}\right.$ for 30 minutes at $37^{\circ} \mathrm{C}$ ) and then fixed with methanol-acetic acid (3:1) at $-20^{\circ}$ C. Nuclear suspensions were dropped onto glass slides, dried at room temperature, and then stained at $4^{\circ} \mathrm{C}$ for 20 minutes with an antifade solution containing DAPI $0.2 \mu \mathrm{g} / \mathrm{mL}$. For evaluation of DNA nuclear content by static cytofluorometry, the intensity of DAPI fluorescence was assessed on $\geq 300$ nuclei in each sample by using a fluorescence microscope equipped with a high-gain photomultiplier (Microphot FX-A with P1, Nikon Corporation, Tokyo, Japan).

On the same nuclei samples, DNA nuclear content was also assessed by image cytometry with a quantitative image-processing system (QUIPS) equipped with a Photometrics Sensys chargecoupled device camera (QUIPS XL Genetic Workstations; Vysis Inc., Downers Grove, IL). For each sample, a variable number of images were acquired with a fixed exposure time, and the DNA nuclear content was evaluated by quantifying the intensity of DAPI fluorescence on $\geq 300$ nuclei. Human nor- 
mal lymphocytes were always used as diploid control, and the DNA index (DI) of each sample was calculated by dividing the mean fluorescence intensity value of the Go/G1 peak by the mean fluorescence intensity value of the Go/G1 peak of human normal lymphocytes. As described by Bauer (23), samples with a DI ranging from 0.9 to 1.2 were classified as diploid. Consequently, samples with a DI ranging from 1.3 to 1.7 were classified as triploid, and samples with a DI ranging from 1.8 to 2.4 were classified as tetraploid. Samples with a DI higher than 1.2 were generally classified as aneuploid. According to Koss et al. (3), the coefficient of variation of each determination, expressed as percentage, was calculated by dividing the mean value of fluorescence intensity of the first peak of the histogram by its standard deviation.

Immediately after ploidy evaluation, slides were washed with PN buffer $\left(0.1 \mathrm{M} N a \mathrm{~N}_{2} \mathrm{PO}_{4} / 0.1 \mathrm{M}\right.$ $\mathrm{Na}_{2} \mathrm{HPO}_{4} / 0.1 \%$ Nonidet P-40, pH 8) for 30 minutes at room temperature, pretreated with $2 \times \mathrm{SCC}$ at $37^{\circ}$ $\mathrm{C}$ for 30 minutes, dehydrated through consecutive washes with ethanol $70 \%, 85 \%$, and $100 \%$ in ice for 2 minutes each, and finally dried overnight at room temperature. After denaturation with $70 \%$ formamide $/ 2 \times \mathrm{SSC}$ at $70^{\circ} \mathrm{C}$ for 2 minutes, dual-color FISH was performed by using (peri)centromeric probes for chromosomes 1(1q12), 7(7p11.1-q11.1), 8(8p11.1-q11.1), 12(12p11.1-q11), 16(16q11.2), 17(17p11.1-q11.1), and/or 18(18p11.1-q11.1), directly labeled with Spectrum-green or Spectrumorange (all from Vysis Inc.). After posthybridization washes with $0.4 \times \mathrm{SSC}$ at $73^{\circ} \mathrm{C}$ for 5 minutes and $2 \times$ SSC/0.1\% NP-40 at RT for 5 minutes, nuclei were counterstained with an antifade solution containing $0.2 \mu \mathrm{g} / \mathrm{mL}$ DAPI. The hybridization signals were analyzed by using a Nikon fluorescence microscope and the QUIPS XL Genetic Workstations (Vysis Inc.). The number of hybridization signals for each probe was determined on $\geq 300$ nuclei for each sample, and the distribution of most frequent chromosome copy numbers determined by FISH was used to define the FISH ploidy pattern of each cell line. After FISH, on the same samples, DNA content was evaluated on at least 300 nuclei by both static cytofluorometry and image cytometry as described above, and the results were compared with those obtained on the same samples before FISH.

\section{Flow Cytometry}

Flow cytometry was performed on cell suspensions fixed with $70 \%$ ethanol at $4^{\circ} \mathrm{C}$. Before staining with $50 \mu \mathrm{g} / \mathrm{mL}$ propidium iodide (Sigma, St. Louis, MO), both tumor cells from OS cell lines and human normal lymphocytes were treated with RNase $0,01 \%$ at $37^{\circ} \mathrm{C}$ for 30 minutes. The intensity of red fluorescence was measured at 625- to 630-nm exci- tation wavelength by using a FACSCalibur flow cytometer (Becton Dickinson, Mountain View, CA). Both ploidy pattern and DI were defined as described above for ploidy assessment by static cytofluorometry and image cytometry.

\section{Metaphase Analysis}

Metaphase spreads were obtained by incubating actively growing OS cell lines with $0.05 \mu \mathrm{g} / \mathrm{mL}$ Demecolcine (Sigma) at $37^{\circ} \mathrm{C}$ for 16 hours. After isolation of metaphases by treatment with hypotonic solution $\left(\mathrm{KCl} 0.04 \mathrm{M}\right.$ for 30 minutes at $37^{\circ} \mathrm{C}$ ) and fixation with methanol-acetic acid (3:1), chromosomes were stained with Giemsa (Sigma). For each cell line, chromosome number was determined on $\geq 50$ metaphases, and the chromosome index (CI) was calculated by dividing the median chromosome number by 46 . The OS cell lines showing a CI ranging from 1.0 to 1.1 (median chromosome number between 46 and 55) were classified as neardiploid, and those showing a CI ranging from 1.2 to 1.6 (median chromosome number between 56 and 75) were classified as near-triploid.

\section{Comparative Genomic Hybridization}

For comparative genomic hybridization (CGH), genomic DNA from OS cell lines (test DNA) and from peripheral blood of a healthy male or female (normal reference DNA) were extracted by standard methods. Test DNA was labeled with FITC and normal reference DNA with Texas Red by nick translation. Equal amounts, corresponding to $1 \mu \mathrm{g}$ of labeled DNA, were coprecipitated together with $10 \mu \mathrm{g}$ of human Cot-I DNA (GIBCO BRL, Gaithersburg, $\mathrm{MD}$ ). DNA samples were cohybridized at $37^{\circ} \mathrm{C}$ for 48 hours on metaphases obtained from human normal lymphocytes, which were previously denaturated with $70 \%$ formamide/ $2 \times$ SSC at $66^{\circ} \mathrm{C}$ for 2 minutes. After posthybridization washes with $50 \%$ formamide $/ 2 \times$ SSC (three times for 10 minutes each at $45^{\circ} \mathrm{C}$ ), $2 \times \mathrm{SSC}$ (two times for 10 minutes each at $\left.45^{\circ} \mathrm{C}\right), 0.1 \times \mathrm{SSC}\left(10\right.$ minutes at $\left.45^{\circ} \mathrm{C}\right), 2 \times$ SSC (10 minutes at room temperature [RT]), $0.1 \mathrm{M}$ $\mathrm{NaH}_{2} \mathrm{PO}_{4} / 0.1 \mathrm{M} \mathrm{Na}_{2} \mathrm{HPO}_{4}$ buffer (10 minutes at RT), and distilled water (10 minutes at RT), samples were counterstained with $0.15 \mu \mathrm{g} / \mathrm{mL}$ DAPI. The hybridization signals were analyzed by using a Zeiss fluorescence microscope and the ISIS digital image analysis system (MetaSystems GmbH, Altlussheim, Germany). Three-color images (green for the tumor DNA, red for the normal reference DNA, and blue for the DNA counterstain) were obtained from $\geq 10$ metaphases for each specimen. Chromosomal regions were considered to be overrepresented when the green-to-red ratio was above 1.17 (gains) or 1.5 
(high-level amplifications) and underrepresented when the ratio was $<0.85$ (losses).

\section{Clinical Samples}

Clinical samples were obtained at biopsy from 11 patients with high-grade OS (including six osteoblastic, three chondroblastic, one fibroblastic, and one telangiectatic OS). To obtain representative cell suspensions, the samples were minced and then digested with $2 \mathrm{mg} / \mathrm{mL}$ type I collagenase (Sigma) for 2 to 4 hours at $37^{\circ} \mathrm{C}$. For assessment of tumor ploidy with static cytofluorometry and image cytometry, cell suspensions were spread on glass slides by centrifugation, fixed with ethanol $70 \%$, and stained with $0.2 \mu \mathrm{g} / \mathrm{mL}$ DAPI at $4^{\circ} \mathrm{C}$ for 20 minutes. Granulocytes, lymphocytes, destructive nuclei, and bone fragments were excluded from the analyses. Ploidy determination by flow cytometry was performed on cell suspensions after RNase treatment and propidium iodide staining, as described for cell lines.

After comparative evaluation of the methods here employed for ploidy assessment, an additional group of 10 OS clinical samples (including three parosteal, low-grade OS, as well as three osteoblastic, one chondroblastic, one fibroblastic, and two telangiectatic, high-grade OS) were analyzed by using static cytofluorometry and image cytometry only.

\section{RESULTS}

\section{Cell Lines}

Ploidy pattern of six human OS cell lines was determined by static cytofluorometry, image cytometry, and flow cytometry (Fig. 1). A complete agreement was found between the three fluorometric methods, which revealed an aneuploid DNA content in all the cell lines, with the level of aneuploidy that was the same by all three methods.

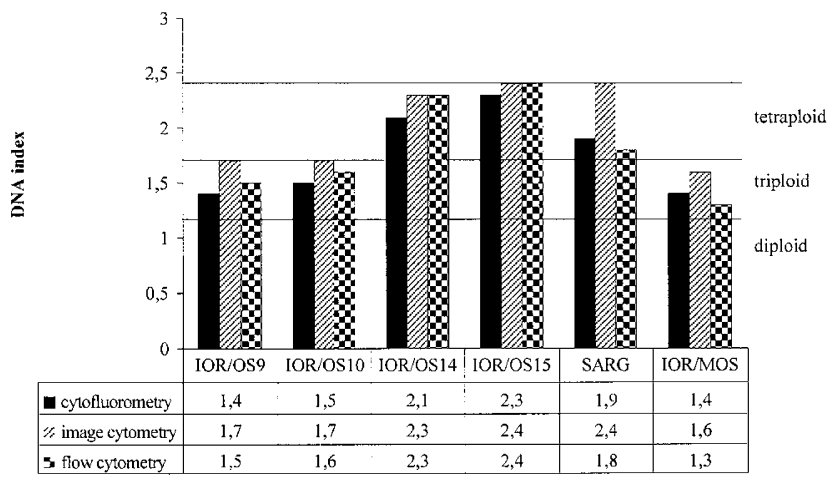

FIGURE 1. Ploidy pattern in human osteosarcoma cell lines as determined by fluorometric methods. Numbers refer to the DNA index as determined by each method.
Three cell lines (IOR/OS9, IOR/OS10, and IOR/ MOS) were triploid, and three (IOR/OS14, IOR/ OS15, and SARG) showed a tetraploid pattern. The mean value for the coefficient of variation was $4.0 \%$ (3.6 to $4.6 \%$ ) for flow cytometry, 4.4 (2.7 to $6.6 \%$ ) for static cytofluorometry, and 4.6 (2.9 to $6.8 \%$ ) for image cytometry, respectively.

By metaphase analysis (Table 1), two cell lines (IOR/OS9 and IOR/MOS) were near-diploid, whereas the other four cell lines showed a neartriploid chromosome number. Metaphase chromosome number distribution agreed with fluorometric determinations of ploidy only in IOR/OS10, being in all the other cell lines lower than the ploidy level defined by fluorometric methods.

FISH ploidy level was determined by using the most recurrent chromosome copy number in each cell line (Table 1). FISH analysis revealed a neardiploid pattern in two cell lines (IOR/OS9 and IOR/ MOS), a near-triploid pattern in three cell lines (IOR/OS10, IOR/OS14, and IOR/OS15), and a neartetraploid pattern in the SARG cell line. The FISH ploidy pattern agreed with the fluorometric ploidy level only in two cell lines (IOR/OS10 and SARG), being in the other four cell lines lower than those determined by fluorometric assessment of DNA content. On the other hand, FISH ploidy agreed with metaphase chromosome number distribution in five cell lines, with SARG being the only exception; it was near-tetraploid by FISH and neartriploid by metaphase analysis. Evaluation of ploidy with static cytofluorometry or image cytometry after FISH did not show any difference compared with the assessment performed before FISH, indicating that the FISH procedure does not influence the DNA content determination with these methods (data not shown).

All the cell lines included in this study were also studied by CGH. As summarized in Table 2, CGH revealed several chromosome aberrations in all cell lines, with a mean value of 16.5 changes per line (range, 14-22) and a mean value of 12.7 chromosomes affected by aberrations per line (range, 1216). Gains were more frequent than losses, with a gains/losses ratio ranging from 1.1 to 3.7 . It is worth noting that IOR/OS14 and IOR/OS15, the two cell lines that showed the most relevant discrepancies between the fluorometric DNA ploidy level and the FISH ploidy pattern or metaphase chromosome number distribution, also showed the highest number of gains and high-level amplifications.

\section{Clinical Samples}

DNA ploidy of clinical OS samples was determined by using flow cytometry on cell suspensions, as well as by static cytofluorometry and image cytometry on cytospins obtained from the same cell 
TABLE 1. Chromosome Copy Number Distribution and Ploidy Pattern in Osteosarcoma Cell Lines According to Metaphase or FISH Analysis

\begin{tabular}{|c|c|c|c|c|c|c|c|c|c|c|}
\hline \multirow{2}{*}{ Cell Line } & \multicolumn{2}{|c|}{ Metaphase Analysis } & \multicolumn{7}{|c|}{$\begin{array}{c}\text { FISH Analysis } \\
\text { Most Recurrent Signal Copy Number (Chromosome) }\end{array}$} & \multirow{2}{*}{$\begin{array}{l}\text { Ploidy Pattern by } \\
\text { FISH }\end{array}$} \\
\hline & $\begin{array}{c}\text { (Median Number of } \\
\text { Metaphase } \\
\text { Chromosomes) }\end{array}$ & $\mathrm{CI}^{a}$ & 1 & 7 & 8 & 12 & 16 & 17 & 18 & \\
\hline IOR/OS9 & Near-diploid (50) & 1.1 & 4 & 2 & 4 & 2 & 2 & 2 & 2 & Near-diploid \\
\hline IOR/OS10 & Near-triploid (56) & 1.2 & 3 & 3 & $3 ; 4$ & 2 & 2 & 3 & 3 & Near-triploid \\
\hline IOR/OS14 & Near-triploid (61) & 1.3 & 3 & 3 & 3 & 2 & 2 & $3 ; 4$ & 3 & Near-triploid \\
\hline IOR/OS15 & Near-triploid (62) & 1.4 & 3 & 6 & 3 & 3 & 2 & $3 ; 6$ & 3 & Near-triploid \\
\hline SARG & Near-triploid (55) & 1.2 & $4 ; 5 ; 6$ & 4 & $4 ; 5$ & $4 ; 6$ & 4 & 4 & 3 & Near-tetraploid \\
\hline IOR/MOS & Near-diploid (52) & 1.1 & 4 & 2 & 2 & 2 & 2 & 2 & 2 & Near-diploid \\
\hline
\end{tabular}

${ }^{a} \mathrm{CI}$, chromosome index; (calculated by dividing the median chromosome number by 46); FISH, fluorescence in situ hybridization.

TABLE 2. DNA Sequence Copy Number Aberrations Detected by Comparative Genomic Hybridization in Human Osteosarcoma Cell Lines

\begin{tabular}{lcccccc}
\hline Cell Line & Aberrations $^{a}$ & $\begin{array}{c}\text { Aberrant } \\
\text { Chromosomes }^{a}\end{array}$ & $\begin{array}{c}\text { High-Level } \\
\text { Amplifications }^{a}\end{array}$ & Gains $^{a}$ & Losses $^{a}$ & \begin{tabular}{c} 
Ratio $_{\text {Gains/Losses }}$ \\
\hline IOR/OS9
\end{tabular} \\
IOR/OS10 & 17 & 12 & 2 & 9 & 8 & 1.1 \\
IOR/OS14 & 14 & 13 & 4 & 10 & 4 & 2.5 \\
IOR/OS15 & 18 & 12 & 10 & 13 & 5 & 2.6 \\
SARG & 14 & 16 & 11 & 9 & 5 & 1.6 \\
IOR/MOS & 14 & 11 & 5 & 11 & 3 & 3.7 \\
\hline
\end{tabular}

${ }^{a}$ Total number.

suspensions that were used for the flow cytometric determination.

A complete agreement was found between static cytofluorometry and image cytometry, whereas discrepancies were found between these two methods and flow cytometry. Aneuploidy was revealed in all the samples by static cytofluorometry and image cytometry and in 9 of 11 samples by flow cytometry (Fig. 2). In three tumors (os-084, os-111, and os113), the ploidy level was lower by flow cytometry than by static cytofluorometry and image cytometry. Moreover, in two of these discordant cases (os-111 and os-113), flow cytometry showed a diploid pattern. Morphological evaluation of these two cell suspensions revealed the presence of a relevant number of normal white blood cells, which may

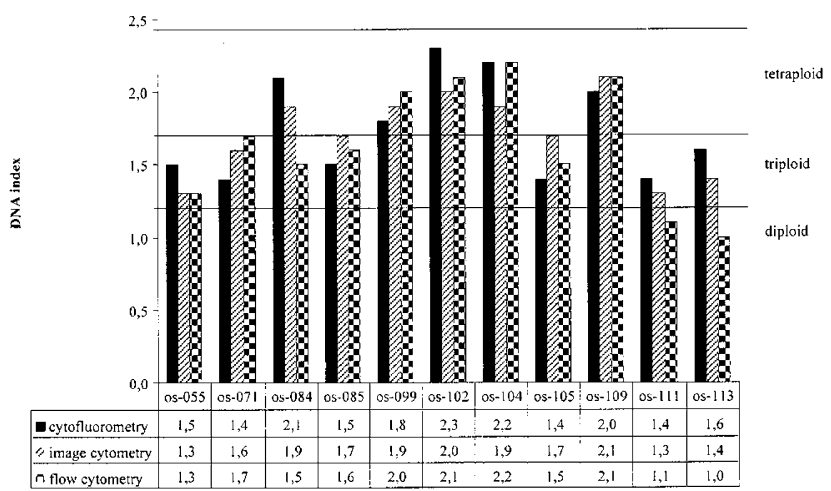

FIGURE 2. Ploidy pattern in human osteosarcoma clinical samples as determined by image cytometry, cytofluorometry, and flow cytometry. Numbers refer to the DNA index as determined by each method. have interfered with flow cytometric assessment but not with the evaluation of DNA ploidy by static cytofluorometry or image cytometry.

On the basis of this evidence, an additional 10 OS clinical samples were analyzed by using cytofluorometry and image cytometry, confirming the complete agreement between these two methods. In this group of clinical samples, a diploid pattern was revealed in $2 / 3$ parosteal, low-grade OS and in $1 / 3$ cases of telangiectatic, high-grade OS.

When considering static cytofluorometry or image cytometry ploidy determinations of all the clinical cases included in this study, aneuploidy resulted in 17/18 (94\%) high-grade tumors (including nine of nine osteoblastic, four of four chondroblastic, two of two fibroblastic, and two of three telangiectatic OS) and in one of three $(67 \%)$ parosteal, low-grade OS.

\section{DISCUSSION}

In this study, we have standardized a method for paired assessment of specific chromosomal copy number changes and DNA ploidy on the same sample of interphase nuclei derived from human OS cells. With this method, it is possible to selectively measure the DNA content only on well-preserved tumor cell nuclei and to use the same specimen to study specific numerical chromosomal aberrations by interphase FISH. This multimodal approach demonstrated that evaluation of DNA ploidy in OS cells is needed for a correct interpretation of FISH 
or cytogenetic data concerning numerical chromosomal changes and that static cytofluorometry or image cytometry can give a more reliable measurement of DNA ploidy in clinical samples containing high proportions of nonneoplastic cells, which cannot be excluded from the flow cytometric assessment.

By using six different human OS cell lines, we found that the ploidy level determined by metaphase analysis or interphase FISH was frequently lower than those evaluated by fluorometric methods. Similar findings, which showed a higher DNA content with fluorometric methods than those expected from metaphase analysis or interphase cytogenetics, have been reported for different tumors, including bone sarcomas (24-26), suggesting that it is a rather common event in several solid neoplasm. A possible explanation for these discrepancies could be the presence of unbalanced chromosomal aberrations, specifically high-level amplifications, which may significantly affect the total DNA content with less effect on the total chromosome number. This fact has to be taken into particular consideration in high-grade OS, which is a tumor characterized by a high frequency of both gains and high-level amplifications involving several chromosomes (27-29). This hypothesis was confirmed in the present study by the CGH analysis of the cell lines. In fact, cell lines showing the highest number of gains and high-level amplifications also showed substantial discrepancies between DNA ploidy level assessed by fluorometric methods and ploidy pattern determined by FISH or metaphase analysis. These OS cell lines showed a high incidence of gains and high-level amplifications spanning several chromosomes' bands (from 10 to 30 megabases to whole chromosome arms), which can significantly affect the total DNA content without such evident changes in chromosome number.

An advantage of the simultaneous assessment of chromosomal numerical aberrations by FISH and of DNA ploidy by cytofluorometry or image cytometry is the possibility for directly relating the copy number of a specific chromosome with the DNA content in each single interphase nucleus. This can be of great help for a correct interpretation of the FISH data. Thus, more precise information can be obtained about the biological relevance of each specific numerical aberration because, for example, a chromosomal trisomy most likely has different biological significance if it occurs in a diploid cell compared with in a tetraploid one. The same comparison between FISH data and DNA ploidy as determined by flow cytometry may be not fully representative because the cell population analyzed for ploidy does not completely overlap the sample used for FISH analysis.
Most of the reported studies concerning ploidy evaluation in OS have been performed by using flow cytometry, and very few studies have combined different methods to perform an accurate evaluation of tumor ploidy in this tumor $(8,24,30)$. However, the use of different, complementary techniques for assessment of DNA content in this neoplasm is highly needed because OS often exhibits extensive numerical chromosomal aberrations, with a considerable variability in chromosome number from cell to cell inside the same lesion as a consequence of a high intratumor heterogeneity (31). Moreover, when the ploidy histogram derived from flow cytometry analysis displays only a diploid peak or a diploid-tetraploid pattern, the representativeness of the cell suspension can be questioned, and only methods like static cytofluorometry or image cytometry may discriminate whether this diploid pattern reflects a mixture of normal and neoplastic cells or rather an exclusive population of diploid tumor cells only (8).

In this study, the evaluation of tumor ploidy in a series of clinical OS samples clearly demonstrated that in high-grade OS, flow cytometry sometimes may give false results because of the presence of high proportions of contaminating, nonneoplastic cells, which cannot be excluded from the assessment. In fact, in two clinical OS samples, flow cytometry showed a diploid pattern, which is very rare in high-grade OS $(7,8,31)$. Morphological evaluation of cell suspensions obtained from these two samples revealed the presence of a considerable proportion of normal white blood cells, which most probably interfered with the flow cytometric assessment of DNA ploidy. Contaminating normal white blood cells do not interfere with the evaluation of DNA ploidy by static cytofluorometry or image cytometry, in which only tumor cells are selected for the analysis. Therefore, static cytofluorometry or image cytometry appear to be the most reliable methods for a correct DNA ploidy evaluation on OS clinical samples. Moreover, also the simultaneous paired analysis of numerical chromosomal aberrations and DNA ploidy is possible by using the method that we standardized on our OS cell lines.

Ploidy analysis of the 21 OS clinical samples included in this study suggested that different ploidy patterns may be related to histologic grading and differentiation, with high-grade lesions showing the most relevant ploidy deviations. However, the biologic relevance of these findings needs to be confirmed on a higher number of OS cases.

In conclusion, the combined application of DNA cytofluorometry and FISH on the same tumor specimen can provide complementary information about genomic changes in OS cells. These methods may also allow the identification of specific chromosomal numerical aberrations that may be rele- 
vant for the malignancy of OS. Moreover, the possibility of assessing specific numerical chromosomal changes in direct relation with DNA content can allow a better evaluation of the clinical impact of specific numerical aberrations, which may be of great help for the identification of new possible prognostic markers for this tumor.

Acknowledgments: The authors thank Dr. Donatella Guardione and Dr. Alessandro Borsatti for the technical assistance.

\section{REFERENCES}

1. Friedlander ML, Hedley DW, Taylor IW. Clinical and biological significance of aneuploidy in human tumours. J Clin Pathol 1984;37:961-74.

2. Merkel DE, Dressler LG, McGuire WL. Flow cytometry, cellular DNA content, and prognosis in human malignancy. J Clin Oncol 1987;5:1690-703.

3. Koss LG, Czerniak B, Herz F, Wersto RP. Flow cytometric measurements of DNA and other cell components in human tumors: a critical appraisal. Hum Pathol 1989;20:528-48.

4. Kreicbergs A, Brostrom LA, Cewrien G, Einhorn S. Cellular DNA content in human osteosarcoma: aspects on diagnosis and prognosis. Cancer 1982;50:2476-81.

5. Kreicbergs A, Silvfersward C, Tribukait B. Flow DNA analysis of primary bone tumors. Relationship between cellular DNA content and histopathologic classification. Cancer 1984;53: 129-36.

6. Look AT, Douglass EC, Meyer WH. Clinical importance of near-diploid tumor stem lines in patients with osteosarcoma of an extremity. N Engl J Med 1988;318:1567-72.

7. Bauer HC, Kreicbergs A, Silfversward C. Prognostication including DNA analysis in osteosarcoma. Acta Orthop Scand 1989;60:353-60.

8. Kreicbergs A. DNA cytometry of musculoskeletal tumors. A review. Acta Orthop Scand 1990;61:282-97.

9. Mankin HJ, Gebhardt MC, Springfield DS, Litwak GJ, Kusuzaki K, Rosenberg AE. Flow cytometric studies of human osteosarcoma. Clin Orthop 1991;270:169-80.

10. Xiang JH, Spanier SS, Benson NA, Braylan RC. Flow cytometric analysis of DNA in bone and soft-tissue tumors using nuclear suspensions. Cancer 1987;59:1951-8.

11. Hopman AH, Moesker O, Smeets AW, Pauwels RP, Vooijs GP, Ramaekers FC. Numerical chromosome 1, 7, 9, and 11 aberrations in bladder cancer detected by in situ hybridization. Cancer Res 1991;51:644-51.

12. Fox JL, Hsu P-H, Legator MS, Morrison LE, Seelig SA. Fluorescence in situ hybridization:powerful molecular tool for cancer prognosis. Clin Chem 1995;41:1554-9.

13. Visakorpi T, Hyytinen E, Kallioniemi A, Isola J, Kallioniemi OP. Sensitive detection of chromosome copy number aberrations in prostate cancer by fluorescence in situ hybridization. Am J Pathol 1994;145:624-30.

14. Kallionemi A, Kallionemi O-P, Sudar D, Rutovitz D, Gray JW, Waldman FM, et al. Comparative genomic hybridization for molecular cytogenetic analysis of solid tumors. Science 1992; 258:818-21.

15. Kallionemi O-P, Kallionemi A, Piper J, Isola J, Waldman FM, Gray JW, et al. Optimizing comparative genomic hybridiza- tion for analysis of DNA sequence copy number changes in solid tumors. Genes Chromosomes Cancer 1994;10:231-43.

16. Piper J. Computer image analysis of comparative genomic hybridization. Cytometry 1995;19:10-26.

17. Bentz M, Plesch A, Stilgenbauer S, Döhner H, Lichter P. Minimal sizes of deletions detected by comparative genomic hybridization. Genes Chromosomes Cancer 1998;21:172-5.

18. Bryndorf T, Kirchhoff M, Rose A, Maahr J, Gerdes T, Karhu R, et al. Comparative genomic hybridization in clinical cytogenetics. Am J Hum Genet 1995;57:1211-20.

19. Scotlandi K, Serra M, Landuzzi L, Baldini N. SARG: a new human osteosarcoma cell line. Expression of bone markers and of major histocompatibility antigens. Ann Oncol 1992; 3(4 Suppl):S29-31.

20. Scotlandi K, Serra M, Manara MC, Lollini P-L, Maurici D, Del Bufalo D, et al. Pre-treatment of human osteosarcoma cells with $\mathrm{N}$-methylformamide enhances P-glycoprotein expression and resistance to doxorubicin. Int J Cancer 1994;58:95101.

21. Manara MC, Scotlandi K, Serra M, Maurici D, Sarti M, Campanacci $\mathrm{M}$, et al. Absence of stimulatory effect of G-CSF on the growth of human sarcoma cells. Int J Oncol 1995;6: 1011-4.

22. Benini S, Baldini N, Manara MC, Chano T, Serra M, Rizzi S, et al. Redundancy of autocrine loops in human osteosarcoma cells. Int J Cancer 1999;80:581-8.

23. Bauer HC. DNA cytometry of osteosarcoma. Acta Orthop Scand Suppl 1988;228:1-39.

24. Tarkkanen M, Nordling S, Bohling T, Kivioja A, Karaharju ES, Elomaa I, et al. Comparison of cytogenetics, interphase cytogenetics, and DNA flow cytometry in bone tumors. Cytometry 1996; 26:185-91.

25. Tribukait B, Granberg-Ohman I, Wijkstrom H. Flow cytometric DNA and cytogenetic studies in human tumors: a comparison and discussion of the differences in modal values obtained by the two methods. Cytometry 1986;7:194-9.

26. Remvikos Y, Gerbault-Seurreau M, Vielh P, Zafrani B, Magdelenat H, Dutrillaux B. Relevance of DNA ploidy as a measure of genetic deviation: a comparison of flow cytometry and cytogenetics in 25 cases of human breast cancer. Cytometry 1988;9:612-8.

27. Tarkkanen M, Karhu R, Kallioniemi A, Elomaa I, Kivioja AH, Nevalainen J, et al. Gains and losses of DNA sequences in osteosarcomas by comparative genomic hybridization. Cancer Res 1995;55:1334-8.

28. Forus A, Weghuis DO, Smeets D, Fodstad O, Myklebost O, Geurts van Kessel A. Comparative genomic hybridization analysis of human sarcomas: II. Identification of novel amplicons at $6 \mathrm{p}$ and $17 \mathrm{p}$ in osteosarcomas. Genes Chromosomes Cancer 1995;14:15-21.

29. Tarkkanen M, Elomaa I, Blomqvist C, Kivioja AH, Kellokumpu-Lehtinen $\mathrm{P}$, Bohling $\mathrm{T}$, et al. DNA sequence copy number increase at 8q: a potential new prognostic marker in high-grade osteosarcoma. Int J Cancer 1999;84: 114-21.

30. Mandahl N, Baldetorp B, Ferno M, Akerman M, Rydholm A, Heim S, et al. Comparative cytogenetic and DNA flow cytometric analysis of 150 bone and soft-tissue tumors. Int J Cancer 1993;53:358-64.

31. Hiddemann W, Roessner A, Wormann B, Mellin W, Klockenkemper B, Bosing T, et al. Tumor heterogeneity in osteosarcoma as identified by flow cytometry. Cancer 1987;59: 324-8. 